\title{
The modes of government guidance for public bicycle operation and state-owned company operation: a case study of Hangzhou city in China
}

\author{
Q. Li \\ Institute of Traffic Management, Department of Public Order, \\ Zhejiang Police College, China
}

\begin{abstract}
The amount of public bicycle use in China has rapidly increased in the last ten years. By the end of 2013, public bicycle projects were operating in at least 70 cities, and there are more than 6 cities with a bicycle population exceeding 10 thousand. However, the local governments implement different public bicycle operation modes, which result in different effects. In this paper, four modes are summarized, including the Beijing mode of company operation, the Wuhan mode of company operation and government limited support, the Shanghai mode of company operation and government purchase, and the Hangzhou mode of government guidance and state-owned company operation. The Hangzhou case study shows that the Hangzhou mode is the best choice for China. Hangzhou is running the largest public bicycle program to date with a noticeable impact in the world. By 2013, 69,750 bikes are used with an average of 5.5 times each day. Most programs have not shown to be economically sustainable while Hangzhou is an exception. The rental, advertising and exporting of techniques guarantee the balance of expense and income in Hangzhou program. Economical sustainability is the key factor of successful application of Hangzhou mode. In future program planning, we suggest that bicycle transportation should be included in the public transportation system, while government guidance and state-owned company operation is the most healthful mode for most of public bicycle projects due to its public service attribution. Moreover, based on the survey results $57.14 \%$ cyclers
\end{abstract}


are not against the increase of rental, we suggest that the rental can be adjusted to improve the income for city-transit policy makers.

Keywords: public bicycle, public transportation, green transportation, traffic priority policy.

\section{Introduction}

Modern public bicycle program has been obtained more and more attention since the well application of a third-generation bike-sharing program in Paris (France) in 2007 [1]. Cycling is regarded as the supplement or competitor of other transit ways, especially for short or mid distance trips. It is also a favourable choice for the transportation policy makers, because cycling can potentially ease traffic congestion and contribute to friendly environment.

Traditionally, China is called a Bicycle Kingdom. In the past peak time, at least $60 \%$ people select cycling as transit way for home or work [2-3]. With the rapid economic growth, urbanization has brought fast increase of the percentage of ownership of private cars and abrupt decrease of the share of cycling over the past 20 years. The percentage of cycling in Beijing decreased from 50.28\% to $19.7 \%$ from 1986 to 2009 [2]. In Hangzhou, with population of 8 million, the share of cycling mode has dropped from $60.78 \%$ in 1997 to $33.5 \%$ in 2007 [3]. As a result of urbanization, the mismatch conflict of road resource has a serious trend. The number of motor vehicles in Wuhan with population of 10 million was hitting 1.2 million while the available parking space was only one third of the vehicle number in 2012 [4]. Energy consumption and clear environment are key factors for Chinese city mayors. The Chinese government goal is to half reduce carbon dioxide emissions in fifteen years from 2005, while it is a great challenge due to the fact that around $6 \%$ vehicle ownership increases on the basis of the

current 200 million vehicles. So public bicycle as Bus Rapid Transit (BRT) and metro becomes an attractive solution to ease traffic pressure, reduce fuel consumption and clear the air.

In the past 7 years, at least 70 cities were promoting the various public bicycle projects [5-7]. Although the local governments have the same purpose to alleviate the traffic congestion, the strategies differ from one city to another. According to the involvement degree of government, it can be categorized into four modes including Beijing mode, Wuhan mode, Shanghai mode and Hangzhou mode.

While most of previous papers discussed the evaluation or impact of public bicycle program, this paper is to focus on the operation mode of public bicycle program, and we put emphasis on the analyse of Hangzhou mode because of the financial success of public bicycle program and its great influence in China.

\section{Public bicycle modes}

Recently, the public bicycle program or bike-sharing has obtained increasing attention in the world. According to the financial involvement degree of local 
government, there are various modes existing in China, including the Beijing mode, the Wuhan mode, the Shanghai mode and the Hangzhou mode.

In the Beijing mode, companies operate the program with limited or no government involvement. Without receiving financial assistance from government, the level of service is closely related with the revenue of program. For the case of little advertising contract, companies generally failed to keep running the service. Three companies in Beijing successively abandoned business after trials at a loss of millions dollars [6-7]. In the Wuhan mode, the government is cost-efficient without needing to fund program, and companies also need to obtain the local government support to use the public space. However, in big cities the public space is usually very expensive. In the Shanghai mode, private companies offer the bike-sharing program and government purchases the service without financial burden. The detriment of this mode is that the companies may not have the same incentive to operate the program as the government if the revenue is not satisfactory [7]. In the Hangzhou mode, the government has the greatest control over the program through a state-owned company providing the service. Because of quasigovernment characteristic, the government maintains the greatest liability for the program. The main purpose of running the program is to provide best service rather than generate revenues for the state-owned company. This mode is discussed in more detail in the next section.

\section{Overview of Hangzhou mode}

Hangzhou, capital of Zhejiang province, with 8 million population and 2.3 million vehicles, also confronts big problems of traffic pressure and environmental pollution. Hangzhou government made many efforts to reduce the use on running car. In the background of public transit priority policy implemented by Chinese central and local government and under the encouragement of Paris's public bicycle program, In May, 2008, Hangzhou launched its public bike program to encourage a shift from cars to bicycles or public transit with 8,000 bikes and 61 stations, which has expanded to 69,750 bikes and 2997 stations including 84 twenty-four-hour service stations in June 2013. In 2011, Hangzhou is awarded as the global top 8 best service of public bicycle by BBC (British Broadcasting Corporation).

The Hangzhou government firstly wanted a first/last mile solution of seamless accessibility by providing the feeder service to public transit. Due to the great acceptance by citizens and potential capacity to ease the traffic jam, it led to the rapid development. Figure 1 shows an impressive growth in bicycle fleet size and station. According to the plan, the scale of size of public bicycle fleet will hit 175,000 in 2020 .

It adopts the 3rd generation based on information technology with characteristics of highly smartness and convenience. It is naturally a free system, because the first hour of use is free while additional fee is charged as 1 yuan RMB ( 0.16 dollar) for the first hour, 2 yuan RMB ( 0.33 dollar $)$ for the second hour and 3 yuan RMB (0.49 dollar) after that. The highest daily use was 402,400 
times with an average of 5.5 times turnover rate per day per bike. Hangzhou mode takes pride in environmental contribution. Based on the fact that average renting time is 33.6 minutes and daily renting amount is 257,500 , Hangzhou government states that this program has daily saved over 125,400 tons of greenhouse gases or been equivalent of car utilization reduction of 68,800 .

All kinds of investigation indicate that public bike program is shifting people toward bike use. While more than $80 \%$ of users were very satisfied with Hangzhou public bike program because of low-cost, automatic check-in and check-out. Around $30 \%$ of investigators incorporated bike-sharing into their most common commute, and a striking result is that $78 \%$ of car owner investigators stated they benefited from bicycle-sharing for trips previously taken by automobile [8].

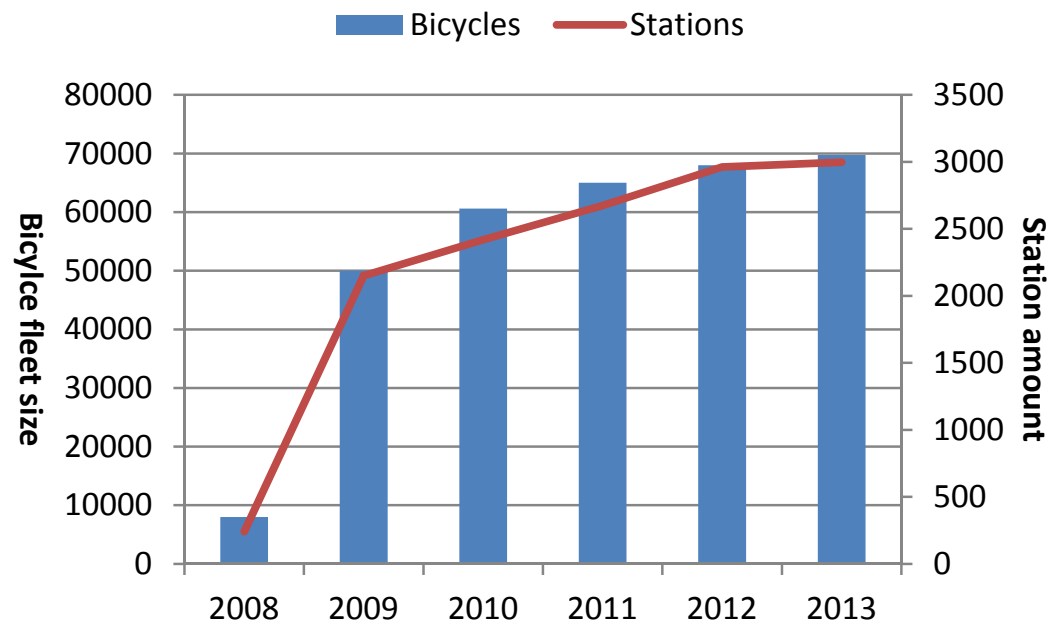

Figure 1: Development of bicycle fleet size and station amount in last 6 years.

\section{Financial sustainability of Hangzhou mode}

We performed interviews with government officials, company managers and users, and obtained the related data from local government statistics.

\subsection{Balance of operating cost}

Apparently, the sustainability of public bike program is a concern, which mainly is closely related to the balance of cost and revenue. Midgley [9] considered that none of the current public bicycle programs can be regarded as a financial success even though they have great contribution on local transit. However, we 
think Hangzhou public bicycle program is an exception, and a better understanding of the Hangzhou mode is necessary.

The financial funding includes capital and operating costs. During the first two years, Hangzhou government deployed 26.4 million dollars to launch the public bicycle program and provided 39.5 million dollars discounted governmental loans to the Hangzhou Public Transport Corporation which is a state-owned enterprise. It is not very difficult to gather so much funding to the just-for-once investment of infrastructure at the development stage of program although the amount is massive, if the local government has enough budgets. The more challenge is the annual operating cost.

The operating cost, depending on the station amount, service area and fleet size, includes the staff salary, fabrication of new stations, purchase or maintenance and distribution of bicycles, office expense. Firstly, a one-speed bike with low-cost is used to limit financial loss from theft and maintenance. The operating cost of Hangzhou public bicycle program in 2009 was nearly 4.39 million dollars, corresponding around 90 dollars per bike on the basis of 500,000 bicycles. The most attractive feature is one hour of free bike-sharing. As a result, the operating data from Hangzhou Public Transport Corporation reveal that $80 \%$ of total trips were made free of charge, and it leaded the whole year renting revenue to be only around 0.81 million dollars. So it is not economic sustainable for any public bicycle program if only depending on the renting income, which is the most main revenue for most programs in China.

Hangzhou made many efforts to balance the expenditure and revenue. By the way of public invitation of bids, a company obtained five-year advertising right of light boxes in the stations and on the bicycle bodies at the cost of 4.3 million dollars with $10 \%$ increase yearly from 2011 to 2015 . Based on the great influence and technology advantage of Hangzhou public bicycle program, export of techniques of Hangzhou mode, including solution design, infrastructure construction and project maintenance, becomes another important income source. The number of exporting city is over twenties, including Ningbo, Jiaxing and Foshan, and the total contracts were valued at 14.3 and 24.2 million dollars in 2011, 2012, respectively. Because of the commercial secrets, we cannot obtain the detailed information of the contract profits.

Along with the increase of bicycle fleet size (In 2020, it is designed to hit 200,000 bicycles), the balance of the operating cost is always the concern of the government and company.

\subsection{Suggestions}

Because of its public characteristic, any public bicycle program should be regarded as a no-profit or few-profit project. However, any company has the minimum requirement of balance of cost and income otherwise satisfactory service cannot be guaranteed. As the above discussion, the main income includes rental, advertising revenue, and charges for technology transfer. While the charges for technology transfer except a few city such as Hangzhou is not 
available for most of cities. Therefore it's the key of economical sustainability to ensure that the rental and advertising revenue can cover the annual operating cost.

Based on the investigation, the percentage of rental is no more than $20 \%$ in Hangzhou, Wuhan. Two surveyors coming from Zhejiang Police College conducted a survey at bike-sharing stations. Total 196 surveys were completed. As shown in Table 1, 82.65\% cyclers control the cycling time in one hour, and $57.14 \%$ cyclers do not care the increase of renting fee. Correspondingly, $79.46 \%$, $16.07 \%, 4.47 \%$ supporters agree to pay $2,3,4$ yuan RMB $(0.33,0.49,0.66$ dollar) respectively. And only $14.28 \%$ objectors will reduce the cycling trips if the fee is increased to 2 yuan RMB ( 0.33 dollar). According to the investigation results, we suggest that the renting income can almost be double increased by setting 2 yuan RMB renting fee in the second hour.

Table 1: The results of the investigation into increasing the second hour rental.

\begin{tabular}{|l|c|c|c|}
\hline Commute with cyclers & Yes & No & Samples \\
\hline Cycling time almost in one hour & 162 & 34 & 196 \\
\hline Agree to increase the second hour rental? & 112 & 84 & 196 \\
\hline $\begin{array}{l}\text { Second hour renting fee is over 4 yuan RMB, do you } \\
\text { agree? }\end{array}$ & 5 & 107 & 112 \\
\hline $\begin{array}{l}\text { Second hour renting fee is over 3 yuan RMB, do you } \\
\text { agree? }\end{array}$ & 23 & 89 & 112 \\
\hline $\begin{array}{l}\text { Will you reduce the cycling trips if rental is } \\
\text { increased to 2 yuan RMB? }\end{array}$ & 12 & 72 & 84 \\
\hline
\end{tabular}

Another suggestion is based on the interviews with Hangzhou Public Transport Corporation. In addition to collecting the revenue from cyclers and advertising companies, subsidy offered by the government based on the level of public bike service may be another source of income, which is an incentive to operating the grogram. Finally, based on the fact that public bicycle program is not a profitable business, state-owned company is more suitable to run the program than private company, especially in China.

\section{Conclusion}

Cycling, as an emission-free transportation alternative, provides efficient first/last mile connectivity which can greatly improve the attractiveness of public transit. Demand of public bike program has been around longer in China with initiative to improve the air quality and ease traffic jam. For city mayors, it is important

to understand which mode is more recommendable for local governments, and more and more Chinese cities generate enormous interest in the Hangzhou mode due to not only the technology advantage but also its financial sustainability. Case study results indicate that bicycle transportation should be included in the public transportation system, while government guidance and state-owned company operation is the most healthful mode for most of Chinese cities due to 
its public service attribute. Long-term and stable government fund is the foundation of sustainable development while the almost-free use with one hour free and extra hour charge is the most effective fee system, and the revenue consists of fee of renting, advertising and technology export. To explore ways to enlarge the revenue of renting and advertising is an important task under the guarantee of the public support. The survey also shows that the citizens are not very sensitive to appropriately increase of rental for the purpose of covering more operating cost share.

\section{Acknowledgements}

This work is supported by the Program for Zhejiang Leading Team of S\&T Innovation. The author also thanks the Hangzhou Public Transportation Corporation and Hangzhou Municipal Statistic Bureau for their assistance with interview and provision of data.

\section{References}

[1] DeMaio P., Bike-sharing: history, impacts, models of provision, and future. Journal of Public Transportation, 12(4), pp. 41-56, 2009.

[2] Beijing Municipal Bureau of Statistics \& NBS Survey Office in Beijing. Beijing statistical yearbook (1986-2009), China Statistics Press: Beijing, 1986-2009.

[3] Hangzhou Municipal Bureau of Statistics, the State Statistical Bureau Hangzhou investigation team \& Hangzhou Social and Economic Investigation Bureau. Hangzhou statistical yearbook (1997-2007), China Statistics Press: Beijing, 1997-2007.

[4] Wuhan Municipal Bureau of Statistics. Wuhan statistical yearbook 2012, China Statistics Press: Beijing, 2012.

[5] Yangjun Z., Urban Bicycle Sharing System Planning. Urban Transport of China, 10(5), pp. 50-54, 2012.

[6] Haixiao P., Yang T., Xianmin M. \& Yujiang M., Overview of bicycle transportation development in urban areas. Urban Transport of China, 8(6), pp. 40-43, 2010.

[7] Yu Z., Xuemin L. \& Hong Z., Urban Public Bicycle System in China: Current Situation, Issues and Countermeasures. China Development, 13(5), pp. 74-79, 2013.

[8] Susan A.S., Hua Z., Elliot M. \& Stacey G., China's Hangzhou public bicycle: understanding early adoption and behavioural response to bikesharing. In Transportation Research Record: Journal of the Transportation Research Board, No. 2247, Transportation Research Board of the National Academies: Wsshington, D.C., pp. 33-41, 2011.

[9] Midgley P., Bicycle-sharing schemes: enhancing sustainable mobility in urban areas, Commission on sustainable development. New York: UN Department of Economic and Social Affairs, 2011. 